Manufacturing Ultra-Precision Meso-Scale Targets by Coining Summary Report

P. J. Davis, M. A. Wall, N. E. Hodge, A. J.

Schwartz

August 4, 2004 
This document was prepared as an account of work sponsored by an agency of the United States Government. Neither the United States Government nor the University of California nor any of their employees, makes any warranty, express or implied, or assumes any legal liability or responsibility for the accuracy, completeness, or usefulness of any information, apparatus, product, or process disclosed, or represents that its use would not infringe privately owned rights. Reference herein to any specific commercial product, process, or service by trade name, trademark, manufacturer, or otherwise, does not necessarily constitute or imply its endorsement, recommendation, or favoring by the United States Government or the University of California. The views and opinions of authors expressed herein do not necessarily state or reflect those of the United States Government or the University of California, and shall not be used for advertising or product endorsement purposes.

This work was performed under the auspices of the U.S. Department of Energy by University of California, Lawrence Livermore National Laboratory under Contract W-7405-Eng-48. 


\section{Manufacturing Ultra-Precision Meso-Scale Targets by Coining Summary Report}

Pete J. Davis, Mark A. Wall, Neil E. Hodge, and Adam J. Schwartz

There exists a certain type of high energy density physics experiment that requires a very precise, one or two-dimensional sinusoidal pattern to be imprinted on the surface of a thin disc-shaped specimen. Early discussions of potential fabrication processes included precision lapping using a substrate with the sinusoidal patterns, diamond turning, and various vapor deposition techniques. The process of coining, in which the sinusoidal pattern is pressed into the surface of a flat disc, was also proposed. Extensive discussions indicated that the low cost of coining and likelihood of success warranted this proof-ofprincipal investigation.

We were tasked with developing a coining technique that would evaluate the feasibility of using a pressing, or coining process to imprint a one-dimensional sinusoidal pattern onto a thin disk specimen. We performed finite element method simulations of the coining process, designed, built, and tested a coining apparatus and tested surrogate materials, and coined a sample of special nuclear material. The preliminary results were encouraging. The pressing of a 3-mm diameter by $\sim 100 \mu \mathrm{m}$ thick disc to 500 pounds of pressure produced a flat part with a $1-\mu \mathrm{m}$ deep by $50-\mu \mathrm{m}$ period sine wave pattern covering all of the surface and thus demonstrated the method for replicating ultraprecision, mesoscale features onto a near-net-shape metallic blank. This coining technique is being developed to provide specialty processing for the manufacturing of difficult to machine, millimeter-size components made from materials that present hazardous conditions. The technology is versatile and can be used to imprint a wide range of features, or profiles into two opposing surfaces. The coining process requires a simple, conceivably hand held tool, which efficiently produces ultra-precision work pieces without the production of byproducts such as machining chips, or grinding swarf. It shows promise for use on ductile materials that cannot be precision machined with conventional single crystal diamond tooling.

The coining apparatus is one element in the work piece forming system. The working elements include instruments to measure both displacement and force (pressure). The instrumented system shown in Figure 1 provides the ability to measure and control the total thickness variation of the sample. The system is designed to be implemented in two modes. During the development phase, the system has provisions for process feedback. Parameters for given materials and shapes can be investigated with the aid of pressure and displacement gauging instruments. Once established, these parameters can be implemented without the aid of some, or all of the electronic instrumentation. This allows the self-contained unit to function in a range of environments. Such a requirement may occur for example, should in-situ annealing be specified. The hardware was designed and built to quickly assess the coining system's effectiveness on a specific class of materials. 


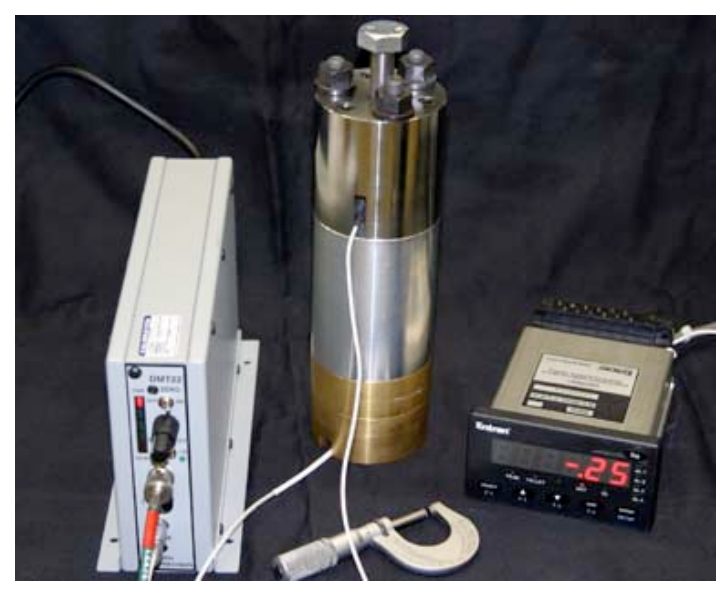

Figure 1. Coining system: capacitance gage amplifier, coining press, and force meter (left to right).

During the coining operation, the coining apparatus will apply a load to the specimen. Initial contact will result in elastic deformation of the specimen as well as some compliance in the apparatus. At some load, the specimen will yield, initiating the process of imprinting the sinusoidal pattern. Continued increase in pressure will increase the level of plastic deformation in the sample. In principle, this process will continue to the point at which the contoured die will fully imprint the desired shape into the sample. Upon unloading, however, elastic deformation of the sample will be released. The amount of springback is likely a function of the elastic modulus of the sample and the compliance of the system. For this reason, finite element simulations were initiated to help guide the design of coining apparatus sinusoidal die. Figure 2 shows the effective plastic strain.

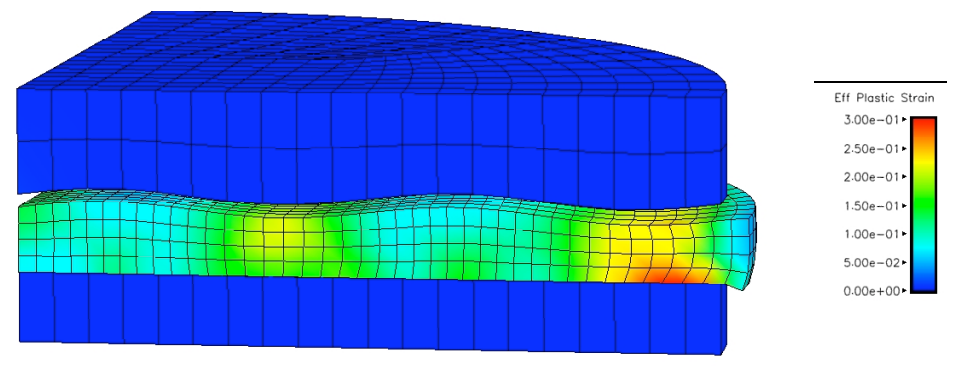

Figure 2: Profile Effects model geometry

A series of demonstration tests were preformed to evaluate coining hardware and process. Three materials were considered: aluminum, a tin-lead alloy, and vanadium.

Metallographic polishing was performed on a 3-mm diameter piece of SNM in order to get a similar surface finish as on the aluminum prior to coining. Difficulties arose during polishing because of the formation of a hydride layer on the surface of the SNM. Ion etching was used to remove the hydride layer, estimated to have been 1-2 $\mu$ m thick. 
The SNM disc was then pressed to 500lbs. As shown in Figure 3, a fairly rough sine wave was pressed into the surface of the SNM sample. The roughness in these images appears to be from the hydride precipitates that formed during preparation that grew down into the grain boundaries of the material, thus not being removed by the ion etching. Secondly, there are groupings of fine scale line features in random directions in the sample. We believe that these may be from a solid-state transformation of the SNM to a different crystal structure. Finally, there are some precipitates in the material and surface debris that appear as black spots in the image.

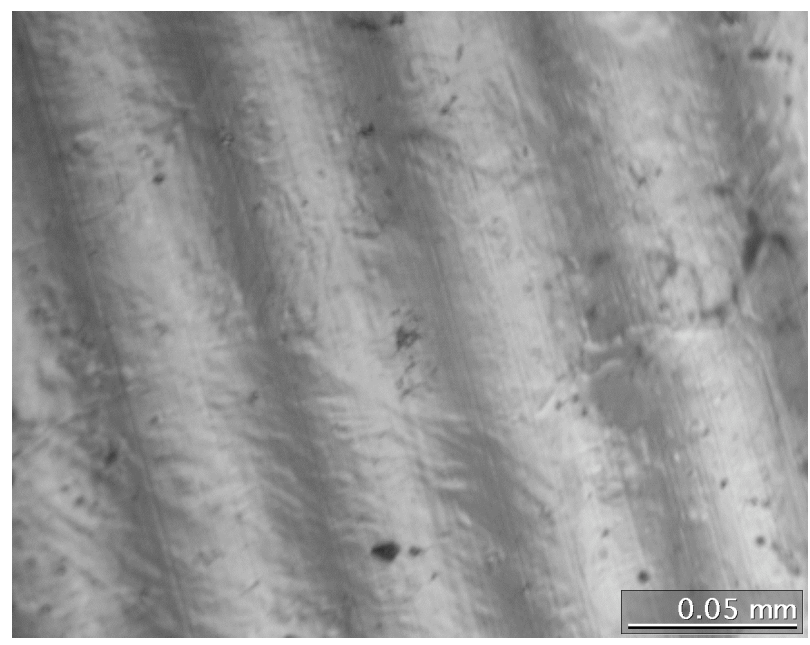

Figure 3. Optical micrograph of the imprinted surface of an SNM sample exhibits fine-scale surface roughness likely due to a partial solid-state phase transformation. 